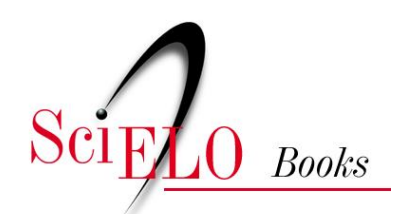

\title{
Experiencias de buenas prácticas \\ 1. Reciclaje de tecnologías de consumo como apoyo a las personas con baja visión
}

\author{
Franklin Aguayo \\ Miriam Gallegos
}

\section{SciELO Books / SciELO Livros / SciELO Libros}

AGUAYO, F., and GALLEGOS, M. Reciclaje de tecnologías de consumo como apoyo a las personas con baja visión. In: GALLEGOS NAVAS, M., ed. La inclusión de las TIC en la educación de personas con discapacidad: relatos de experiencias [online]. Quito: Editorial Abya-Yala, 2019, pp. 47-53. ISBN: 978-9978-10-495-8. https://doi.org/10.7476/9789978104958.0004.

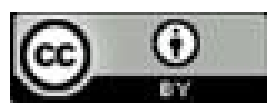

All the contents of this work, except where otherwise noted, is licensed under a Creative Commons Attribution 4.0 $\underline{\text { International license. }}$

Todo o conteúdo deste trabalho, exceto quando houver ressalva, é publicado sob a licença Creative Commons Atribição 4.0.

Todo el contenido de esta obra, excepto donde se indique lo contrario, está bajo licencia de la licencia $\underline{\text { Creative }}$ Commons Reconocimento 4.0. 


\title{
Experiencias de buenas prácticas
}

\section{Reciclaje de tecnologías de consumo como apoyo a las personas con baja visión}

"Nadie se educa a sí mismo todos se educan en comunidad"

(P. Freire)

\begin{abstract}
Fundación Baja Visión Ecuador
Ecuador

Quito

Responsable: Franklin Aguayo

Gestores de la práctica: La experiencia se desarrolló con los miembros del equipo de optómetras de la institución especializados en el tema de baja visión y se enfoca en poner al alcance de las personas con baja visión ayudas técnicas de bajo costo, que les permita una adecuada inclusión en el ámbito educativo y social.

Para ello se desarrolla una estrategia alternativa de reutilización de dispositivos electrónicos de consumo masivo tales como: teléfonos digitales o tabletas que están a la mano de la mayoría de la población, pero se desconoce que pueden ser utilizarlos como herramientas de apoyo en la rehabilitación visual instalando en ellos varios programas y aplicaciones tecnológicas gratuitas que permiten transformar estos dispositivos en magnificadores electrónicos, que pueden ser introducidos en el ámbito educativo gracias a su versatilidad, convirtiéndose en una herramienta fundamental para para enfocar imágenes tanto de lejos como de cerca.
\end{abstract}

\section{Motivación}

La Fundación Baja Visión Ecuador, es una organización no gubernamental que brinda los servicios de rehabilitación integral a personas con baja visión, busca potencializar la visión funcional de las personas diagnosticadas con baja visión. Una de las acciones constituye la configuración de apoyos visuales de grandes potencias como: lupas, telesco- 
pios, microscopios, lupas electrónicas, circuitos cerrados de televisión, entre otras, las cuales son prescritas luego de la evaluación realizada por el equipo de baja visión conformado por el medico oftalmólogo, optometrista y rehabilitador visual; con los resultados de la evaluación el profesional en rehabilitación visual, ejecuta el proceso de estimulación y/o rehabilitación visual en el cual se enseña a la persona a potenciar su visión a través del uso de la ayuda prescrita.

Una de las principales barreras a las que se enfrenta la población con baja visión en el Ecuador es no contar con las ayudas ópticas y no ópticas necesarias. La mayoría no se producen en el país y su importación las encarece haciéndolos poco accesibles a personas de escasos recursos económicos.

\section{Objetivos}

Potenciar el remanente visual de las personas con baja visión para que puedan desenvolverse con mayor autonomía en las actividades de la vida cotidiana.

\section{Desarrollo de la experiencia}

a. Identificación de tecnologías de consumo: esta actividad consiste en identificar tecnologías de consumo tales como teléfonos móviles o tabletas, que ya no se utilicen y que permitan la adaptación de nuevas funciones que permitan el acceso a la información de las personas con discapacidad visual.

b. Descargar el software gratuito: procedemos a realizar la descarga del software Súper Visión de la siguiente dirección electrónica: https://goo.gl/ZvMgT9; este programa es de uso gratuito. 
Figura 9

Software Super Visión

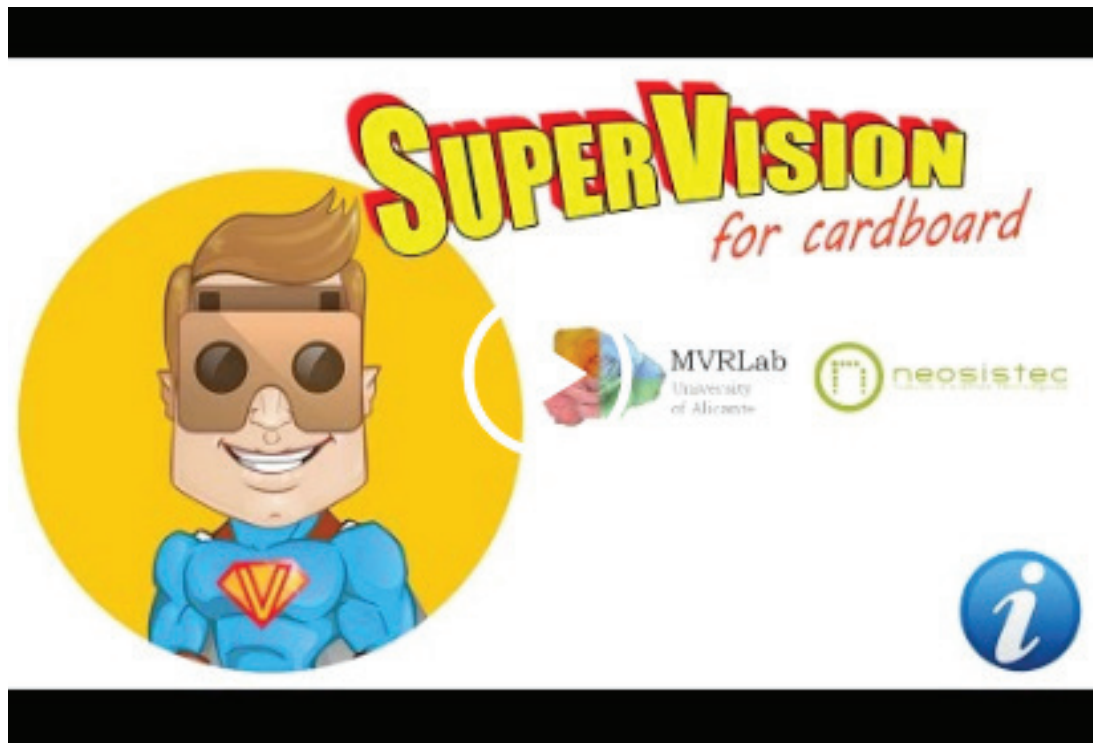

Fuente: SuperVisión mini - Google play. Recuperado de https://goo.gl/TFVozk

c. Una vez instalado el programa el menú principal del dispositivo móvil (Tablet, celular), aparecerá en el menú principal el siguiente icono:

Descargado el software en el teléfono o Tablet, se cuenta con tres posibilidades de aplicación:

- Utilizarlo como lupa electrónica: para ampliación de textos y de imágenes a corta distancia y a su vez para actividades de lectura y escritura, para lo cual dispone de control del zoom, 9 modos de color, puede usarse en entornos de poca iluminación gracias a la activación de flash. 


\section{0}

Figura 10

Uso de software en una Tablet

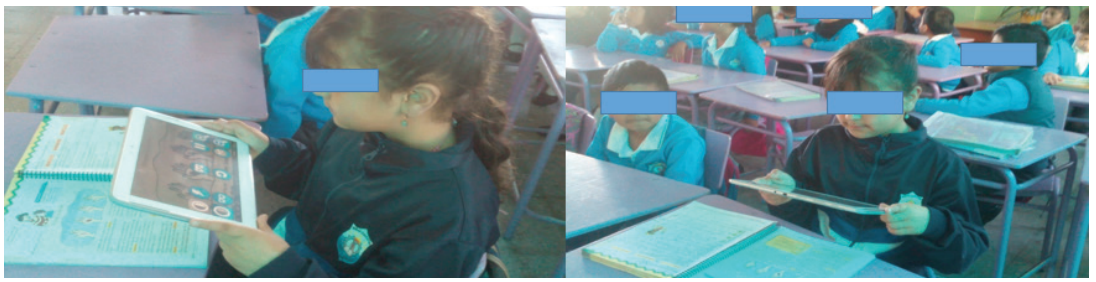

Fotos: Franklin Aguayo (2016)

Figura 11

Menú de Configuración del software

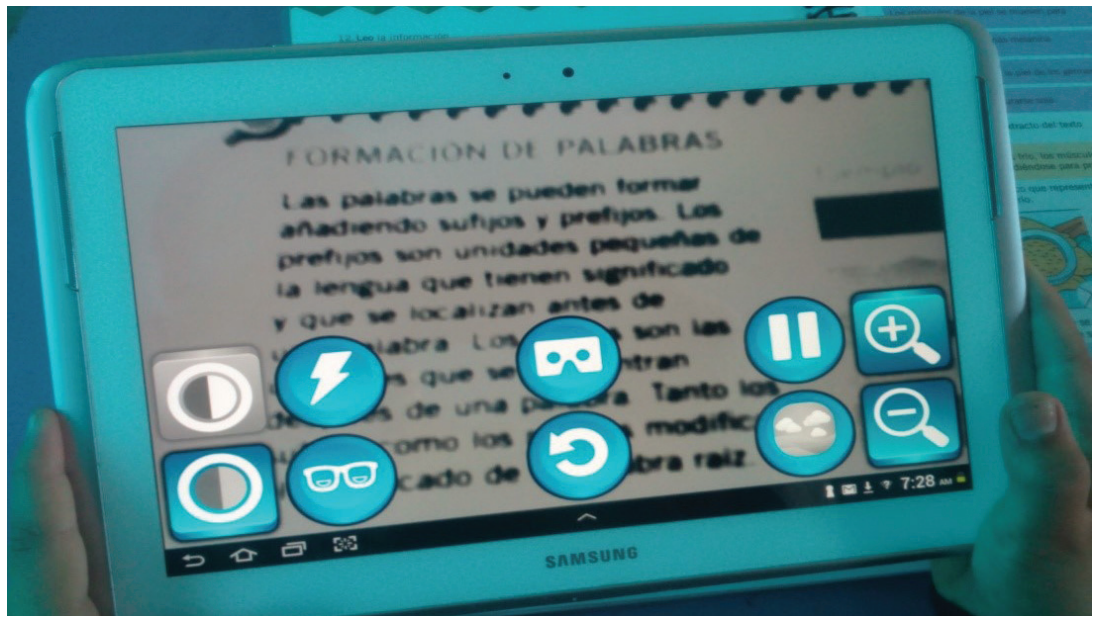

Foto: Franklin Aguayo (2016)

- Utilizarlo como telescopio: para amplificar las imágenes a la distancia, cumpliendo funciones de telescopio electrónico y que puede ser usado para mirar el pizarrón, letreros, direcciones de calles, nombres de autobuses, etc. 


\section{1}

Figura 12

Ejemplo de utilización del software

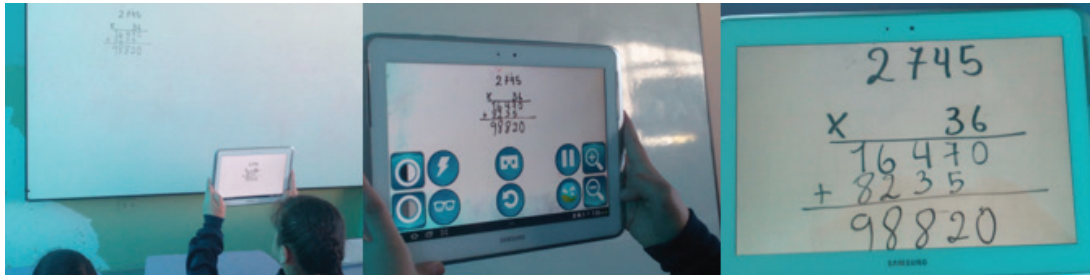

Fotos: Franklin Aguayo (2016)

- Utilizarlo como gafas electrónicas bifocales: para simulación virtual que permite un enfoque tanto de lejos como de cerca con visión estereoscópica simulando una ayuda técnica de visión artificial, gracias a la capacidad de detectar el movimiento de cabeza y el cambio de enfoque a diversas distancias, las diferentes funciones pueden ser controladas por medio de un teclado conectado por bluetooth.

Figura 13

Uso de gafas electrónicas bifocales

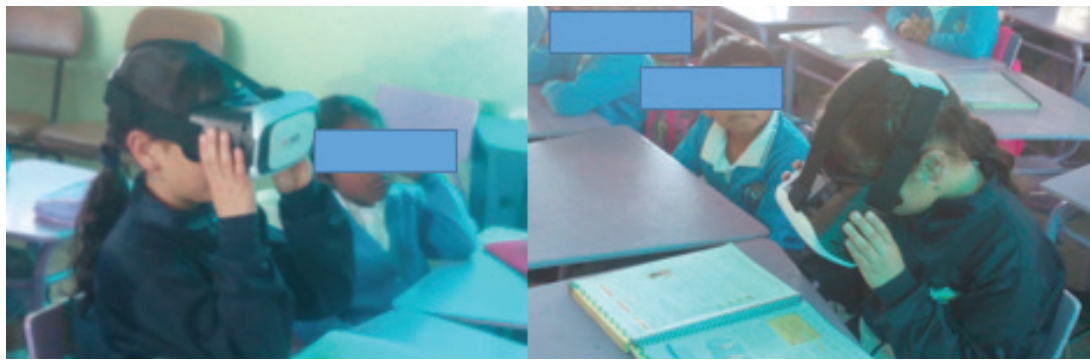

Fotos: Franklin Aguayo (2016)

- Utilizarlo como lector óptico de caracteres: para las personas con discapacidad visual severa, podemos utilizar esta tecnología con un software denominado OCR, (reconocimiento óptico de 


\section{2}

caracteres), que permite al dispositivo transformarse en un escáner y convertir un archivo de imagen (fotografía del texto) a un archivo de texto y este a su vez en un archivo audible que permita escuchar el texto que fue capturado por el dispositivo.

\section{Logros obtenidos}

Para determinar los logros alcanzados en los procesos de rehabilitación visual, se midió la agudeza visual y necesidades del grupo seleccionado antes y después del proceso de rehabilitación; los niños que al inicio tenían agudeza visual desde (AV. 20 /60 e inferiores) hasta discapacidad visual grave, agudezas visuales (20/800) lograron mejorar y llegar a agudezas visuales de 20/30 y 20/100-20/50 respectivamente en visión próxima, es decir, consiguieron una visión suficiente para desenvolverse adecuadamente en el aula de clases y poder continuar con sus estudios en las instituciones de educación regular a las cuales fueron asignados, por otra parte también mejoró su rendimiento académico al finalizar el período escolar respectivo.

La utilización de esta lupa electrónica avanzada de bajo costo, permitió a los estudiantes amplificar la imagen del objeto o texto observado, tanto en visión próxima como en visión lejana, cumpliendo la función de lupa y de telescopio electrónico, versatilidad que ha posibilitado el acceso a la información de libros, folletos, leer etiquetas, precios, firmar, escribir, ver letreros, nombres de autobuses, nombres de calles, entre otras aplicaciones con ciertas limitación producidas por su discapacidad.

Utilizado con una carcasa (Cardboard), ${ }^{13}$ permite adaptar a los ojos a modo de gafas de realidad virtual, controlar los diferentes modos de contraste y la función de zoom la misma que da una apariencia de una gafa bifocal, permitiendo manejar el enfoque de lejos y cerca. Todo esto ha hecho que los estudiantes puedan acceder a la información así

13 Disponible en: https://goo.gl/7jkfPs 
como también adquieran un adecuando desenvolvimiento en actividades de la vida diaria, en actividades escolares esta función permite manejarse adecuadamente en el aula de clase ya que sentado en el pupitre, puede magnificar o ampliar la pizarra y en el caso de bajar la vista al escritorio, el dispositivo cambia automáticamente el enfoque para facilitar la lecto-escritura.

Los estudiantes con baja visión acogieron con mucho entusiasmo el uso de estos apoyos en el aula, se evidenció la colaboración de los docentes para evitar que los equipos sufran daños ya que los estudiantes sentían curiosidad de los mismos. De igual manera las familias están muy contentas con la yuda recibida ya que el rendimiento escolar de sus hijos está al nivel de sus compañeros.

\section{Aplicaciones informáticas para el aprendizaje de inglés en universitarios con discapacidad visual}

"Dime y lo olvido, enséñame y lo recuerdo, involúcrame y lo aprendo" (Benjamín Franklin)

Universidad Politécnica Salesiana

Ecuador

Quito

Responsable: Cristian Castañeda

Gestores de la práctica: Tiflobiblioteca UPS

Esta experiencia presenta estrategias metodológicas para el aprendizaje de una segunda lengua de los estudiantes con discapacidad, con cinco estudiantes con discapacidad visual que cursan diversas carreras en la Universidad Politécnica Salesiana del Ecuador, sede Quito

\section{Motivación}

Para el aprendizaje de una segunda lengua de los estudiantes con discapacidad en la universidad, requieren que los docentes utilicen diferentes estrategias metodológicas en sus clases, para cubrir las expec- 